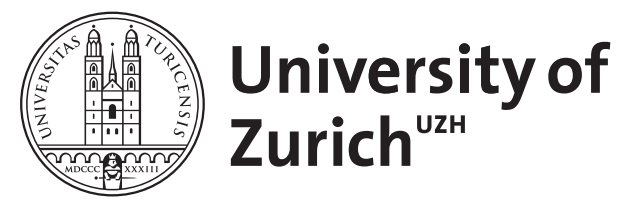

\title{
Metastases in Meckel's cave
}

Theuer, Susanne E ; Krayenbühl, Niklaus ; Scheffel, Hans ; Yonekawa, Yasuhiro ; Kollias, Spyros S

\begin{abstract}
Metastases in Meckel's cave are a rare tumor entity and should be considered as important differential diagnosis, especially if the patient presents with trigeminal neuralgia and suffers from a known primary malignancy. We present three cases of patients with secondary trigeminal neuralgia caused by a metastasis in Meckel's cave, treated by microsurgery and fractionated radiation therapy. Differential diagnoses are discussed on the basis of preoperative neuroradiological imaging. MRI is the preferred diagnostic modality, whereas complementary CT may be needed for evaluation of early bone invasion
\end{abstract}

DOI: https://doi.org/10.1007/s00062-007-7004-6

Posted at the Zurich Open Repository and Archive, University of Zurich ZORA URL: https://doi.org/10.5167/uzh-156488

Journal Article

Published Version

Originally published at:

Theuer, Susanne E; Krayenbühl, Niklaus; Scheffel, Hans; Yonekawa, Yasuhiro; Kollias, Spyros S (2007). Metastases in Meckel's cave. Clinical Neuroradiology, 17(1):41-47.

DOI: https://doi.org/10.1007/s00062-007-7004-6 


\title{
Metastases in Meckel's Cave
}

\section{A Challenge of Differential Diagnosis}

\author{
Susanne E. Theuer', Niklaus Krayenbühl², Hans Scheffel ${ }^{3}$,Yasuhiro Yonekawa², \\ Spyros S. Kollias ${ }^{1}$
}

\begin{abstract}
Metastases in Meckel's cave are a rare tumor entity and should be considered as important differential diagnosis, especially if the patient presents with trigeminal neuralgia and suffers from a known primary malignancy. We present three cases of patients with secondary trigeminal neuralgia caused by a metastasis in Meckel's cave, treated by microsurgery and fractionated radiation therapy. Differential diagnoses are discussed on the basis of preoperative neuroradiological imaging. MRI is the preferred diagnostic modality, whereas complementary CT may be needed for evaluation of early bone invasion.
\end{abstract}

Key Words: Meckel's cave $\cdot$ MR-imaging $\cdot$ Diagnostic neuroradiology

Clin Neuroradiol 2007;17:41-7

DOI 10.1007/s00062-007-7004-6

\section{Metastasen im Cavum Meckeli. Eine differentialdiagnostische Herausforderung}

\section{Zusammenfassung}

Das Cavum Meckeli ist ein seltener Manifestationsort tumoraler Metastasen. Bei Patienten mit bekannter maligner Tumorerkrankung, die unter einer Trigeminusneuralgie leiden, sollte jedoch die Metastasierung des Cavum Meckeli in differentialdiagnostische Betrachtungen einbezogen werden. Wir präsentieren drei Fälle mit sekundärer Trigeminusneuralgie infolge Metastasierung des Cavum Meckeli. Alle drei Patienten wurden mittels Mikroneurochirurgie und fraktionierter Radiotherapie behandelt. Die Magnetresonanztomographie ist die Methode der Wahl in der Evaluation neuroradiologischer Differentialdiagnosen. Die Computertomographie ist sehr hilfreich zur Beurteilung knöcherner Arrosionen.

Schlüsselwörter: Cavum Meckeli · MRT · Diagnostische Neuroradiologie

\section{Introduction}

Meckel's cave is a cerebrospinal fluid (CSF) filled space in a small depression anterior to the petrous apex formed by two layers of the dura mater. The trigeminal nerve enters through an oval dural opening, the porus trigeminus, in the posterior wall of this cavity [1]. The nerve trunk, composed of numerous small fibres, expands to form the sickle-shaped trigeminal (Gasserian or semilunar) ganglion, which lies in the anterior-inferior aspect of Meckel's cave and occupies $10 \%$ of its space. The leptomeninges form the trigeminal cistern, a subarachnoid space filled with CSF surrounding the nerve and ganglion within Meckel's cave.

Distal to the Gasserian ganglion the trigeminal nerve trifurcates into its main branches: the ophthalmic (V1), maxillary (V2) and mandibular (V3) nerves. The ophthalmic and maxillary divisions course within the cavernous sinus along its lateral wall before they run extracranially via the superior orbital fissure and the foramen rotundum, respectively. The mandibular nerve

\footnotetext{
Institute of Neuroradiology, University Hospital of Zurich, Zurich, Switzerland,

${ }^{2}$ Department of Neurosurgery, University Hospital of Zurich, Zurich, Switzerland,

${ }^{3}$ Institute of Diagnostic Radiology, University Hospital of Zurich, Zurich, Switzerland.
}

Received: October 24, 2006; accepted: January 7, 2007 
does not transverse the cavernous sinus but travels in a short segment anterior-inferiorly along the skull base and exits through the foramen ovale [2].

A diverse array of pathologies can involve the trigeminal nerve. Differential diagnosis depends on lesion location, the patient's history and clinical symptoms, as well as imaging characteristics. Tumors in Meckel's cave are rare lesions. Schwannomas and meningiomas represent the majority of masses at this site. Other rare entities include lymphoma and perineural spread of tumor [3]. In distinction to this last entity, which occurs as a continuous spread of head and neck cancer along the branches of the trigeminal nerve, we report three cases of hematogenous or CSF metastases in Meckel's cave rarely reported up to now.

\section{Case Reports}

We report three cases, two male, one female, mean age 61 (51 to 71 years), with a metastasis in Meckel's cave spreading along the trigeminal nerve. In two patients a primary tumor was known (breast and clear cell kidney cancer). In the third patient, despite extensive tumor

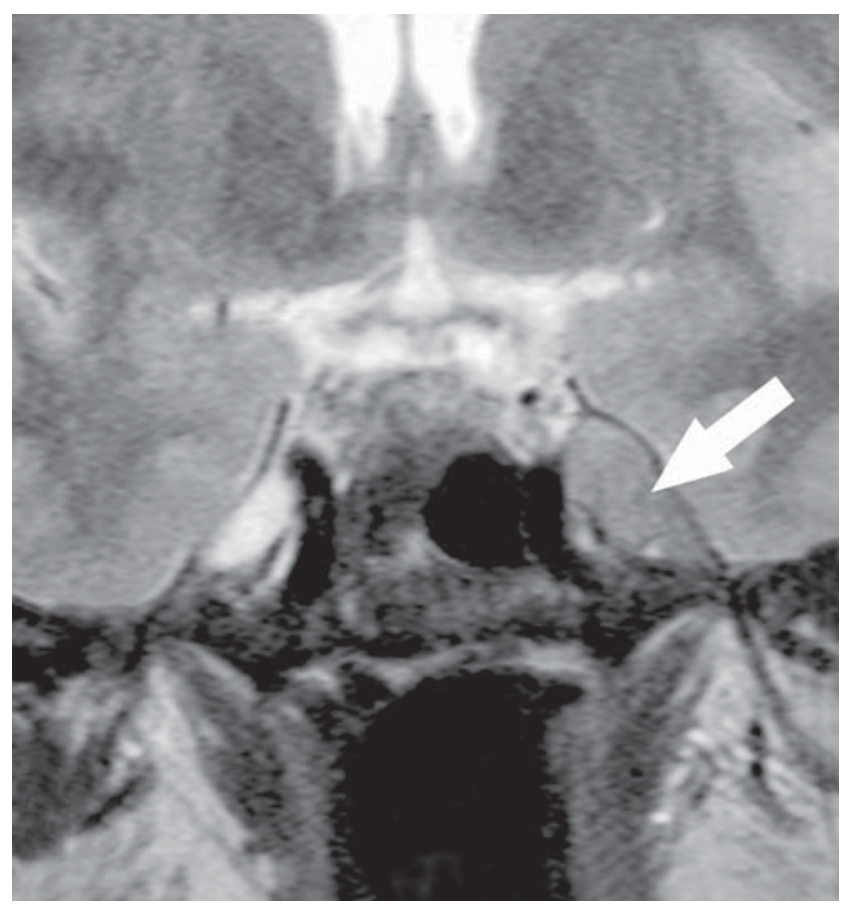

Figure 1a searching, no primary tumor site was found, but histological and immunohistochemical examination with expression of cytokeratins and p53 showed clear evidence of a carcinoma metastasis. All patients were treated with surgery and fractionated radiation therapy.

At admission, all patients presented with trigeminal neuralgia in two or three trigeminal roots, lasting from one month to one year. Pain could be triggered by touch and analgesia dolorosa was found in the same region. Two patients did not show any corneal reflex on the affected side. Additionally, one patient showed a palsy of the third, forth and sixth cranial nerves, progressive over the last six month. Preoperatively contrast-enhanced MR scans were performed in all patients.

\section{Case 1}

Case 1 was a 51-year-old female with known breast cancer suffering from trigeminal neuralgia in all three trigeminal roots. She did not show any corneal reflex. MR-imaging showed a tumorous lesion along the trigeminal nerve in its cisternal, prepontine segment and Meckel's cave (Figures 1a and b). Its anatomical exten-

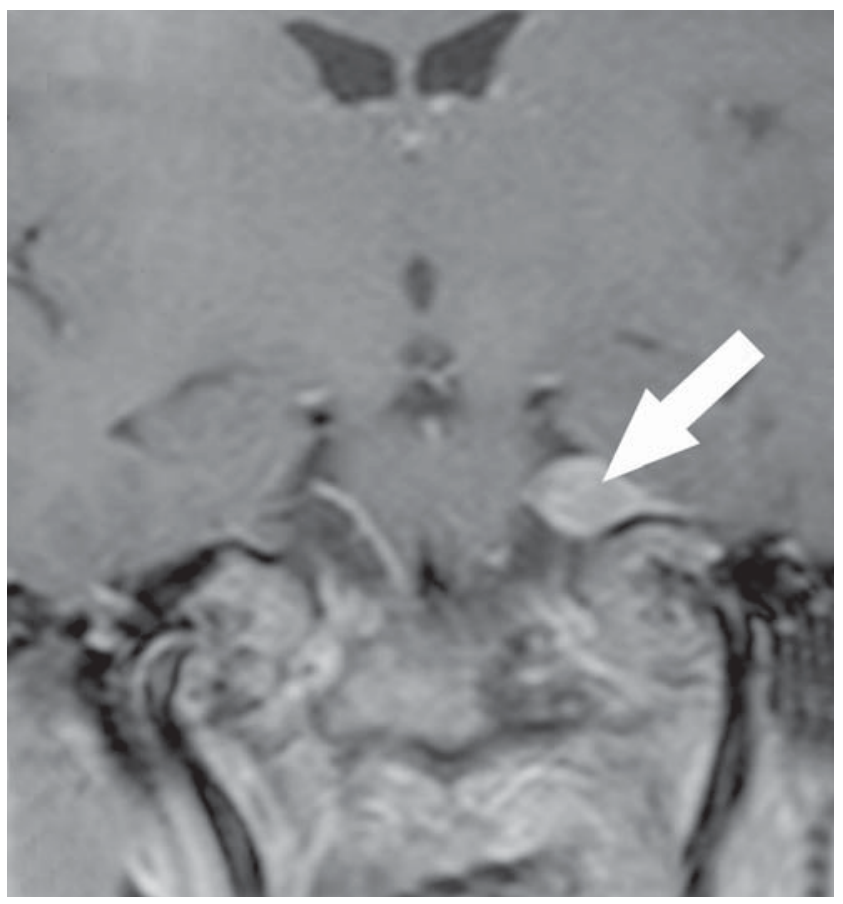

Figure $1 b$

Figures 1a and 1b. Patient 1: A 51-year-old woman after resection of a breast cancer. a) Coronal T2-weighted MR-image at the level of the optic chiasm shows a cortex isointense lesion (arrow) within the Meckel's cave, deforming its normal anatomic appearance and involving the trigeminal ganglion. Neither infiltration of the cavernous sinus nor infratemporal extension was detected. The lesion was attached to the petrous apex, although the bony cortical outlines were preserved. b) Contrast-enhanced coronal T1-weighted, fat-saturated MR-image at the level of the pons demonstrates the enhancing mass (arrow) in the anterior aspect of the left cerebellopontine cistern infiltrating the trigeminal rootlets. 
sion to the superior orbital fissure, the foramina rotundum and ovale with infiltration and slight dilatation of the latter correlated with clinical findings. These findings suggested the differential diagnosis of a metastatic brain tumor or a trigeminal (ganglionic) schwannoma. Left-sided transzygomatic subtemporal approach with anterior petrosectomy was performed with gross total tumor removal. Postoperative the patient showed complete pain relief, but newly presenting third nerve palsy with mydriasis, ptosis and double vision, as well as a sixth nerve palsy which was not present before surgery.

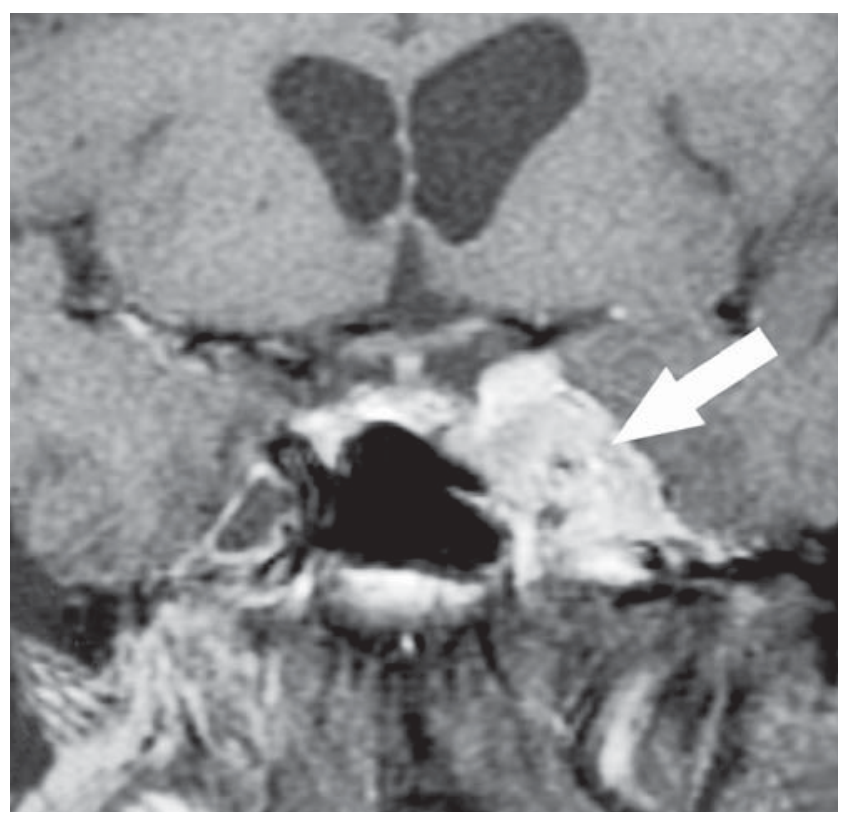

Figure 2a

Figures 2a to 2c. Patient 2: A 71-year-old man after resection of clear kidney cancer. a) Contrast-enhanced coronal T1-weighted, fat-saturated MR-image shows an enhancing lesion (arrow) within the left Meckel's cave and cavernous sinus, bulging the lateral dura of Meckel's cave, infiltrating the posterior-lateral aspect of the sphenoidal sinus, foramina rotundum and ovale. b) Axial T2-weighted MR-image depicts an inhomogeneous, cortex hyperintense, extra-axial mass (arrows) containing multiple, intratumoral vessels consistent with flow voids. The tumor obliterates the Meckel's cave and extends anterior along all the foramen rotundum and posterior in the cerebellopontine cistern. The tumor tissue extended to the orbital apex, the horizontal segment of the bony carotid channel and the cerebellopontine angle cistern, with compression of the lateral surface of the pons and mesencephalon. c) Axial bone-window CT-image reveals the concentric expansion of the foramen ovale (arrow). Bony erosion and destruction of the middle cranial fossa beneath the trigeminal ganglion with expansion of the foramen rotundum was also present.
Histopathologic examination revealed metastases of breast cancer.

\section{Case 2}

Case 2 was a 71-year-old male after resection of clear cell kidney cancer presenting trigeminal neuralgia in all trigeminal roots. The clinical presentation was associated with the imaging findings which showed a mass lesion involving the entire left-sided Meckel's cave and the cavernous sinus (Figures $2 \mathrm{a}$ to $2 \mathrm{c}$ ). Paramedian occipito-suboccipital craniotomy on the left side was per-

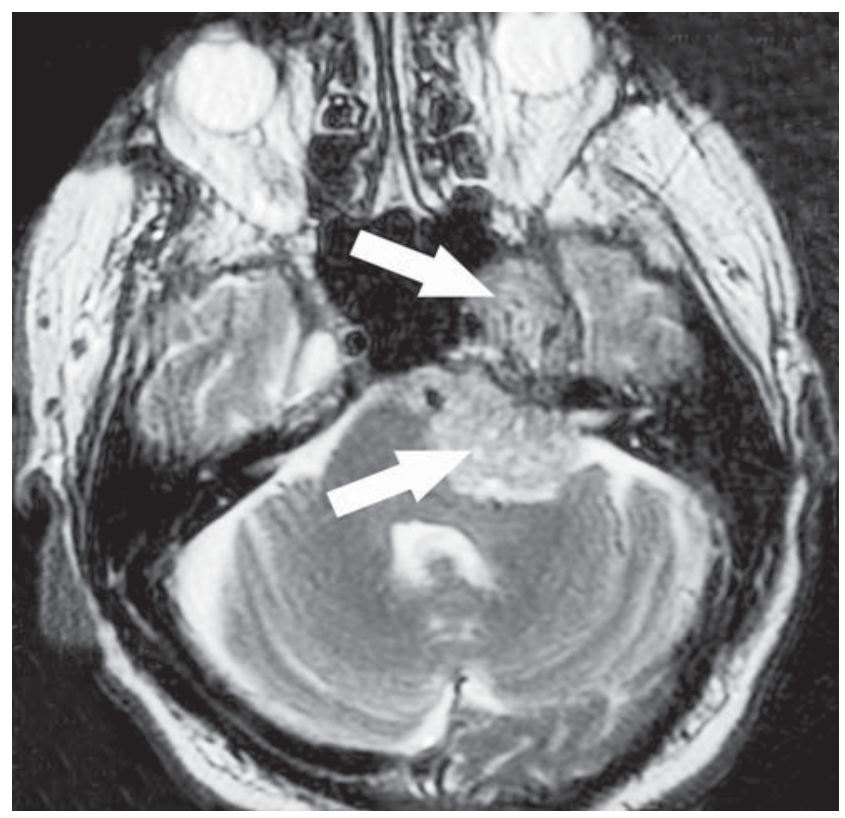

Figure $\mathbf{2 b}$

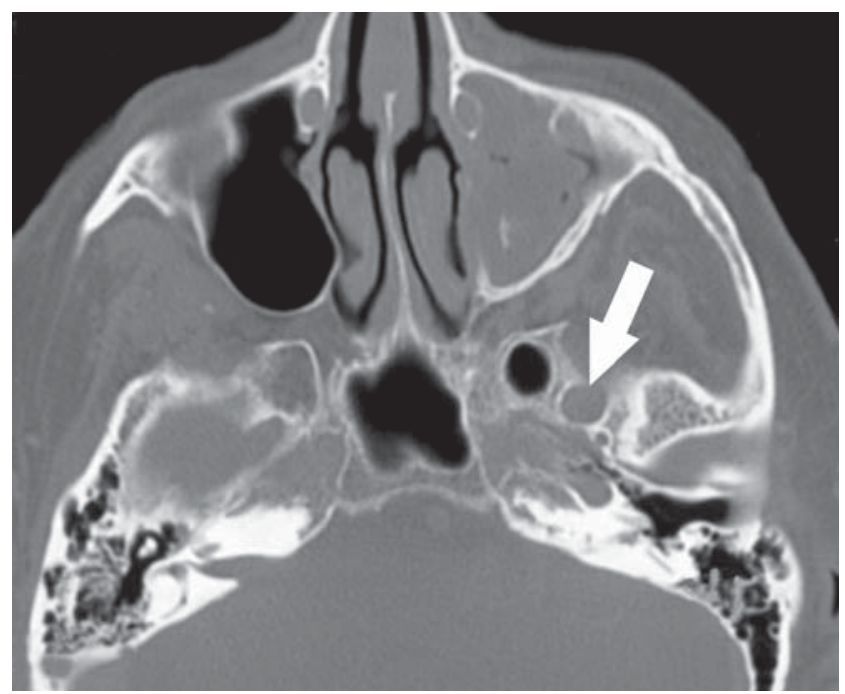

Figure 2c 
formed, but the surgery had to be stopped because of air embolism. In a second operation with the same approach, subtotal tumor removal was performed with a small tumor rest left in Meckel's cave. Histopathologic examination showed metastasis of clear kidney cancer. Because of pulmonary embolism the postoperative re-

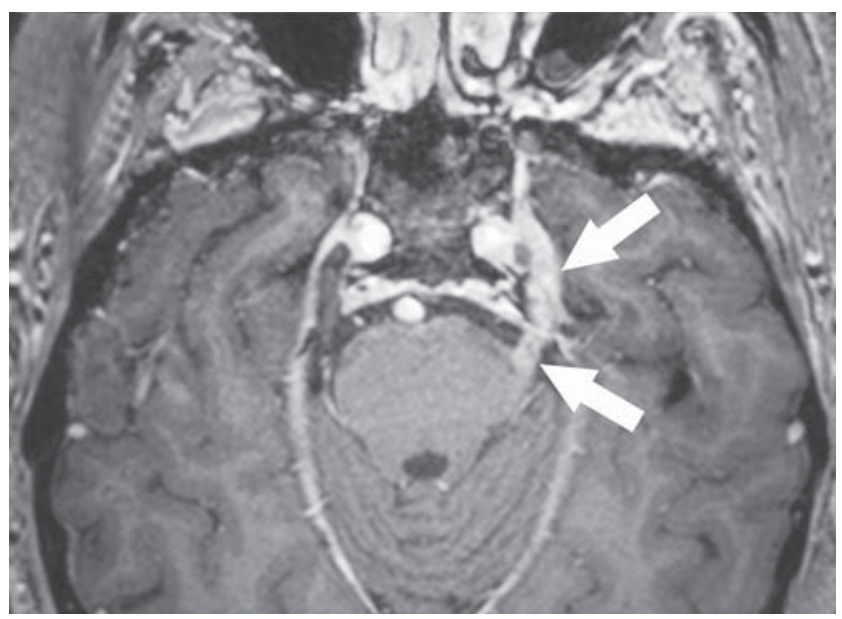

Figure $3 a$

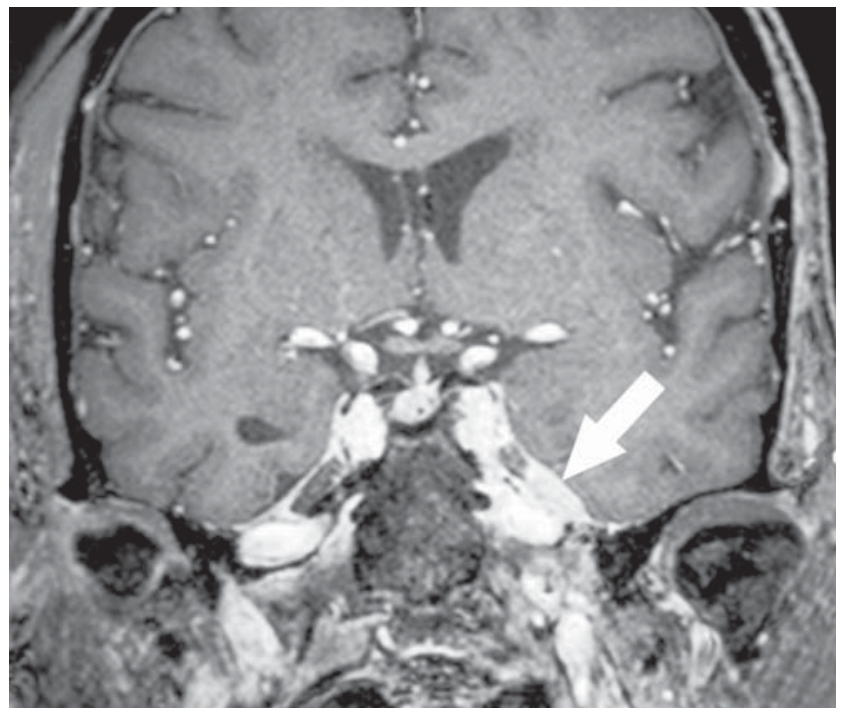

Figure $\mathbf{3 b}$

Figures $3 \mathbf{a}$ and $\mathbf{3} \mathbf{b}$. Patient 3: A 61-year-old man with a metastasis of an oat cell carcinoma of unknown origin. a) Contrast-enhanced axial T1weighted, fat-saturated MR-image demonstrates an intense enhancing, enlarged left trigeminal nerve (arrows) from its root entry zone via cisternal segment to porus trigeminus and lateral aspect of Meckel's cave. b) Contrast-enhanced coronal T1-weighted, fat-saturated MR-image shows infiltration of the trigeminal ganglion by a homogenously enhancing mass (arrow) in the inferior-anterior-lateral aspect of Meckel's cave. Note enhancement and thickening of the mandibular nerve extending from the trigeminal ganglion slightly extracranially via the foramen ovale to the masticator space. The normal CSF signal of Meckel's cave is diminished. covery was delayed. The patient had an unchanged ophthalmoplegia, but also new dysarthria.

\section{Case 3}

Case 3 was a 61-year-old male with clinical manifestation of trigeminal neuralgia in the second and third trigeminal root and ophthalmoplegia. Imaging findings revealed a mass lesion involving the Meckel's cave (Figures $3 \mathrm{a}$ and $\mathrm{b}$ ). Left frontotemporal craniotomy and subtotal tumor removal was performed, as the entire Meckel's cave and part of cavernous sinus were infiltrated by the tumor. As intraoperative monitoring showed no response in the motor root, part of the mandibular nerve was resected together with the tumor. Postoperative a slight reduction in trigeminal pain was found in this case. Metastasis of an oat cell carcinoma was revealed by histopathologic examination.

\section{Discussion}

The Meckel's cave may be affected either by extrinsic or intrinsic disease. Extrinsic lesions, usually bony metastases, chordoma or chondrosarcoma, destroy the adjacent bone and compress or secondarily infiltrate the Meckel's cave. Intrinsic lesions expand Meckel's cave. When the tumor becomes large enough, exerted pressure leads secondarily to erosion of the surrounding bone. Lesions may also directly extend away from Meckel's cave along the trigeminal branches with enlargement of the foramina rotundum and ovale or of the superior orbital fissure. Intrinsic lesions include primary tumors of the Meckel's cave as well as secondary neoplasms either from perineural spread of head and neck malignancies or from leptomeningeal or hematogenous spread of a distant malignancy. Primary tumors of the Meckel's cave are most frequent, usually benign and include trigeminal schwannomas and meningiomas [4]. Other lesions described in this site like amyloid, cholesteatoma, fibrous xanthoma, melanocytoma and malignant melanotic schwannoma have very low incidence.

Trigeminal neuralgia involving all three divisions of the nerve is the most common primary symptom of a Meckel's cave neoplasm [5-7], but clinical findings do not allow accurate localization of the lesion [8]. Therefore, the entire course of the trigeminal nerve must be visualized from the brainstem origin to the peripheral endplates. MR-imaging is considered the method of choice for evaluating patients with trigeminal nerve disorders in most clinical settings [9] because it detects the full ex- 
tent of lesion especially in the basal cisterns and skull base [10] and displays intradural tumor components.

MR-imaging was the primary modality used for the investigation of the three above mentioned patients with trigeminal neuralgia. In the first two cases medical history and lesion morphology were considered to be consistent with metastatic disease. Metastatic pathways through which malignant tumors involve the trigeminal nerve or ganglion can be divided into CSF dissemination, hematogenous spread from extracranial primary sites and continued invasion from extracranial malignancies such as nasopharyngeal, maxillo-facial and infratemporal fossa tumors via the adjacent dura or bone [11]. The occurrence of metastases in Meckel's cave is described for esophageal and colorectal adenocarcinoma as well as breast carcinoma [5, 6, 12]. Intracranial metastases of the ophthalmic (V1), maxillary (V2) and mandibular (V3) nerves or the trigeminal nerve trunk have been reported previously with follicular carcinoma of the thyroid [13], systemic lymphoma [14], hepatocellular carcinoma, ovarian cancer and melanoma of the skin [15-17].

Brain metastases from breast cancer are among the most common hematogenous metastases and occur typically 42 to 60 months after the diagnosis of the primary lesion - a longer period than other types of cancer [12]. This is in consistence with our first case of breast cancer presenting symptoms of trigeminal neuralgia 48 months after primary tumor resection, whereas in the patient with kidney cancer symptoms arised 15 months after resection of the primary tumor.

In the case of the woman suffering from breast cancer the radiographic characteristics of the lesion in the middle cranial fossa were interpreted as being consistent with schwannoma, or even malignant schwannoma, or a lymphoma, too. Schwannomas of the trigeminal nerve are the second most common cranial nerve schwannomas. These usually isolated lesions present with loss of function of the affected nerve segment but they can also be clinically silent. The slight foraminal enlargement in our case made the diagnosis of schwannoma possible. Primary malignant schwannomas of the trigeminal nerve are rare entities, especially starting from the trigeminal ganglion [18].

Malignant lymphomas can also arise in the trigeminal nerve, spread into the Meckel's cave or through the foramen ovale. They are also isointense on T1- and T2weighted MR-images with homogenous gadolinium enhancement. Primary central nervous system lymphoma is rare but can affect the cavernous sinus and Meckel's cave especially in high-risk immuno-compromised [19, 20]. De Pena et al. described an isolated lymphoma metastasis involving the cisternal segment of the trigeminal nerve and the Gasserian ganglion via CSF [21]. In most cases concomitant involvement of other cranial nerves is present at the time of diagnosis.

Metastasis from kidney cancer in Meckel's cave has not been previously reported. The strongly enhancing, infiltrative, partially irregular marginated lesion in the second patient was also suspected of a hemangiopericytoma due to the presence of multiple intralesional flow voids. Hemangiopericytomas are rare intracranial, dural-based, malignant tumors, representing 2 to $4 \%$ of meningeal tumors. They show multilobular or irregular margins, strong contrast enhancement and typically no signs of calcification or hyperostosis, an important distinguishing feature [22].

An exceptionally rare entity to include in a differential diagnosis is the granular-cell-tumor (granularcell myeloblastoma) of the trigeminal nerve. Carvalho et al. reported a case of this tumor on the level of trigeminal ganglion and Meckel's cave that invaded the cavernous sinus, enlarged the foramen ovale, partially destroyed the petrous apex and enhanced homogenously [23].

The third patient had no history of a primary malignancy. This made the correct diagnosis more challenging. Enhancement of the trigeminal ganglion is normal and routinely visible on MR-images [24]. Occasionally even the normal proximal V2 or V3 divisions and nerve sheath may enhance $[1,8]$. This should not be confused with pathologic entities particularly if the patients are asymptomatic. The combination of enhancement and enlargement of a nerve is pathologic due to inflammatory or infectious disorders, such as inflammatory pseudotumor, viral neuritis, sarcoidosis and histiocytosis. Whereas neurosarcoidosis can involve the trigeminal nerve or ganglion, viral encephalitis, herpes neuritis and Lyme disease affect the preganglionic, cisternal segment, too [4]. The involvement of this trigeminal nerve segment in the third patient led us to the primary diagnosis of an inflammatory process.

A tumoral process was also included in the differential diagnosis. Because of the relatively circumscribed lesion morphology and the minimal meningeal enhancement we considered a schwannoma as a more likely diagnosis than a meningioma. Meningiomas of Meckel's cave can involve the Gasserian ganglion or/and the pre- 
ganglionic, cisternal segment as well as the main branches of the trigeminal nerve and meningiomas en plaque embedded in the ganglion have been described [7]. On MRI meningiomas and metastases appear as isointense in T2-weighted images and iso- to hypointense lesions in T1-weighted images with an intense contrast enhancement. Apparent dural tail and hyperostosis as distinguishing feature of a meningioma were not found in our case. This makes the differential diagnosis more difficult, especially if there are no coexisting brain metastases and therefore a possible metastasis was included in the differential diagnosis.

Similar imaging characteristics are also found with other neoplastic diseases, such as perineural tumor infiltration. Imaging signs of perineural tumor extension along the trigeminal nerve include abnormal nerve thickening with enhancement, concentric expansion or erosion of related skull base foramina and extracranial nerve canals. Furthermore replacement of the normal trigeminal cistern hypointensity on T1-weighted or hyperintensity on T2-weighted images by an isointense mass, enhancement within Meckel's cave, the trigeminal cistern or at the root entry zone of the trigeminal nerve, lateral bulging of the cavernous sinus and dural membranes, and denervation atrophy of the masticator muscles $[1,25,26]$. Perineural tumor extension is most commonly seen with head and neck carcinomas of cutaneous and mucosal origin, particularly the squamous cell carcinoma, adenoid cystic carcinoma, malignant melanoma and basal cell carcinoma [25, 27]. Additional tumor types like lymphoma, mucoepidermoid carcinoma, adenocarcinoma and sarcoma, schwannoma and neurofibroma are reported to spread retrogradely via perineural route and to reach eventually the foramen ovale [8]. The mandibular division of the trigeminal nerve is most commonly involved because of its extensive branches and connections involving the facial structures and neck [26]. Peritumoral spread in the Gasserian ganglion occurs in $40 \%$ of patients with malignant peripheral lesions, by far the most often being squamous cell carcinoma of the face [10].

Perineural tumor spread into Meckel's cave is best seen on post-contrast coronal T1-weighted images using fat saturation. The MR-study of our third patient revealed a smooth, isointense thickening of V3 and moderate concentric enlargement of the foramen ovale. The replacement of the normal signal intensity of the trigeminal cistern in T1-weighted images by an isointense mass indicated ganglionic involvement.
It is important that perineural tumor spread alters treatment and prognosis. Surgical removal of these tumors enables the confirmation of the diagnosis and amelioration of trigeminal pain. In consideration of the postoperative quality of life, the radicality of surgical treatment should be planned according to the tumor extension and possibly combined with adjuvant radiation therapy.

We conclude that knowledge of the anatomic course of the trigeminal nerve as well as patient's history facilitate early diagnosis, correct estimation of tumor extend and guide the appropriate treatment. Despite metastasis of Meckel's cave, Gasserian ganglion and trigeminal nerve is rare, it should be taken into differential diagnostic thinking, especially in patients with a known primary malignancy.

High-resolution MR-imaging should be used to follow tumor spread along the nerve, its adjacent structures and potentially intradural extent. CT provides additional information related to involvement of the bony skull base foramina.

\section{References}

1. Sohn Williams L, Schmalfuss IM, Sistrom CL, Inoue T, Tanaka R, Seoane ER, Mancuso AA. MR imaging of the trigeminal ganglion, nerve, and the perineural vascular plexus: normal appearance and variants with correlation to cadaver specimens. AJNR Am J Neuroradiol 2003; 24:1317-23.

2. Harnsberger HR. Imaging of the skull base and cranial nerves. In: Handbook of head and neck imaging, 2nd ed. Mosby, St. Louis 1995, pp 397-542.

3. Tacconi L, Arulampalam T, Johnston F, Symon L. Adenocarcinoma of Meckel's cave: case report. Surg Neurol 1995;44:553-5.

4. Kamel HA, Toland J. Trigeminal nerve anatomy: illustrated using examples of abnormalities, AJR Am J Roentgenol 2001;176:247-51.

5. Mastronardi L, Lunardi P, Osman Farah J, Puzzilli F. Metastatic involvement of the Meckel's cave and trigeminal nerve. A case report. J Neurooncol 1997;32:87-90.

6. Mewes H, Schroth I, Deinsberger W, Boker DK. Pain of the trigeminal nerve as the first symptom of a metastasis from an oesophagus carcinoma in Meckel's cave - case report. Zentralbl Neurochir 2001; 62:65-8.

7. Nijensohn DE, Araujo JC, MacCarty CS. Meningiomas of Meckel's cave. J Neurosurg 1975;43:197-202.

8. Majoie CB, Hulsmans FJ, Verbeeten B Jr, Castelyns JA, Oldenburger F, Schouwenburg PF, Andries Bosch D. Perineural tumor extension along the trigeminal nerve: magnetic resonance imaging findings. Eur J Radiol 1997;24:191-205.

9. Majoie CB, Verbeeten B Jr, Dol JA, Peeters FL. Trigeminal neuropathy: evaluation with MR imaging. Radiographics 1995;15:795-811.

10. Hutchins LG, Harnsberger HR, Hardin CW, Dillon WP, Smoker WRK, Osborn AG. The radiologic assessment of trigeminal neuropathy. AJNR Am J Neuroradiol 1989;10:1031-8.

11. Albayram S, Adaletli I, Selcuk H, Gulsen F, Islak C, Kocer N. Breast cancer metastasis involving pterygopalatine fossa: a cause of trigeminal neuralgia. Headache 2004;44:927-8. 
12. Hirota N, Fujimoto T, Takahashi M, Fukushima Y. Isolated trigeminal nerve metastases from breast cancer: an unusual cause of trigeminal mononeuropathy. Surg Neurol 1998;49:558-61.

13. Kachhara R, Nair S, Radhakrishnan VV, Pandey M, Ahmed MI, Kumar A, Bhattacharya RN. Solitary metastasis from occult follicular carcinoma of the thyroid mimicking trigeminal neurinoma - case report. Neurol Med Chir(Tokyo) 2001;41:360-3.

14. Inatomi $Y$, Inoue $T$, Nagata $S$, Matsuno $H$, Itoh $Y$. Trigeminal neuralgia caused by the metastasis of malignant lymphoma to the trigeminal nerve: a case report. No Shinkei Geka 1998;26:401-5.

15. Aung TH, Po YC, Wong WK. Hepatocellular carcinoma with metastasis to the skull base, pituitary gland, sphenoid sinus, and cavernous sinus. Hong Kong Med J 2002;8:48-51.

16. Harkness KA, Manford MR. Metastatic malignant melanoma presenting as a cavernous sinus syndrome. J Neurol 2004;251:224-5.

17. Merimsky 0, Inbar M, Groswasser-Reider I, Neudorfer M, Chaitchik S. Sphenoid and cavernous sinuses involvement as first site of metastasis from a fallopian tube carcinoma. Case report. Tumori 1993;79:444-6.

18. Moeller HC, Heiland M, Vesper M, Hellner D, Schmelzle R. Primary solitary malignant schwannoma of the trigeminal nerve. Report of a case and review of the literature. Mund Kiefer Gesichtschir 1999;3:331-4.

19. Abdul Aziz KM, van Loveren HR. Primary lymphoma of Meckel's cave mimicking trigeminal schwannoma: case report. Neurosurgery 1999; 44:859-62.

20. Kinoshita M, Izumoto S, Oshino S, Nonaka M, Moriuchi S, Maruno M, Yoshimine T. Primary malignant lymphoma of the trigeminal region treated with rapid infusion of high-dose MTX and radiation: case report and review of the literature. Surg Neurol 2003;60:343-8.

21. De Pena CA, Lee Y-Y, van Tassel P. Lymphomatous involvement of the trigeminal nerve and Meckel's cave: CT and MR appearance. AJNR Am J Neuroradiol 1989;10:S15-7.
22. Akiyama M, Sakai H, Onoue H, Miyazaki Y, Abe T. Imaging intracranial haemangiopericytomas: study of seven cases. Neuroradiology 2004; 46:194-7.

23. Carvalho GA, Lindeke A, Tatagiba M, Ostertag H, Samii M. Cranial granular-cell tumor of the trigeminal nerve. Case report. J Neurosurg 1994; 81:795-8.

24. Downs DM, Damiano TR, Rubinstein D. Gassserian ganglion: appearance on contrast-enhanced MR. AJNR Am J Neuroradiol 1996;17:237-41.

25. Chang PC, Fischbein NJ, McCalmont TH, et al. Perineural spread of malignant melanoma of the head and neck: clinical and imaging features. AJNR Am J Neuroradiol 2004;25:5-11.

26. Laine FJ, Braun IF, Jensen ME, Nadel L, Som PM. Perineural tumor extension through the foramen ovale: evaluation with MR imaging. Radiology 1990;174:65-71.

27. Ginsberg LE, DeMonte F. Imaging of perineural tumor spread from palatal carcinoma. AJNR Am J Neuroradiol 1998;19:1417-22.

\author{
Address for Correspondence \\ Hans Scheffel, MD \\ Institute of Diagnostic Radiology \\ University Hospital of Zurich \\ Raemistraße 100 \\ 8091 Zürich \\ Switzerland \\ Phone (+41/44) 255-8958, Fax -4443 \\ e-mail: Hans.Scheffel@usz.ch
}

